\title{
The effect of genetic variants affecting NK cell function on cardiovascular health and the burden on CMV
}

Shelley Waters ${ }^{1 *}$, Silvia Lee ${ }^{1,2}$ *, Jacquita S Affandi ${ }^{3}$, Ashley Irish ${ }^{4,5}$, Patricia Price ${ }^{1}$

${ }^{1}$ School of Biomedical Science, Curtin University, Bentley, Australia

${ }^{2}$ Department of Microbiology and Infectious Diseases, Pathwest Laboratory Medicine

${ }^{3}$ School of Public Health, Curtin University, Bentley, Australia

${ }^{4}$ Renal Unit, Fiona Stanley Hospital

${ }^{5}$ School of Medicine and Pharmacology, University of Western Australia

*These authors contributed equally to the manuscript

\section{Corresponding author:}

A/Professor Patricia Price

School of Biomedical Science

Curtin University

Bentley WA 6102

Australia

Tel: +61 892669716

Email: patricia.price@curtin.edu.au

\section{Key words:}

Cytomegalovirus, Natural killer cells, Renal transplantation.

\section{Short title:}

NK cell genotypes, vascular health and CMV

\section{Abbreviations}

CIMT: Carotid intimal media thickness, CMV: Cytomegalovirus, FMD: Flow mediated dilatation, HLA: Human leucocyte antigen, LIR-1 or LILRB1: Leukocyte immunoglobulin-like receptor 1, MHC: Major histocompatibility complex, NK: Natural killer, RTR: Renal transplant recipient, SNP: Single nucleotide polymorphism 


\subsection{Abstract}

Renal transplant recipients (RTR) display high burdens of cytomegalovirus (CMV) and accelerated cardiovascular change. NK cells can control CMV and may contribute to vascular pathologies. Polymorphisms in genes encoding the inhibitory receptor LIR-1 and its ligand HLA-G, and the activating receptor NKG2C may illuminate the role of NK cells in vascular health and CMV immunity. We assessed 81 healthy adults and 82 RTR $>2$ years after transplantation. RTR had higher humoral and T-cell responses to CMV, and impaired vascular health. A 14bp indel in HLA-G associated with increased flow-mediated dilatation of the brachial artery. The T allele of LILRB1 rs1061680 associated with increased carotid intimal media thickness (cIMT) in RTR and controls. A 16kb deletion encompassing the NKG2C gene associated with lower cIMT values and higher humoral and T-cell responses to CMV. Hence all polymorphisms tested had small but discernable effects on vascular health. The NKG2C deletion may act via CMV.

150 words 


\subsection{Introduction:}

Infections with cytomegalovirus (CMV) are very common - indeed $40-90 \%$ of all adults are CMV seropositive [1]. Infections are usually asymptomatic in healthy individuals, but the virus becomes latent and persists with periodic reactivations generating immune activation and accelerated T-cell differentiation [2]. CMV is also implicated in the progression of several diseases of aging. Evidence linking persistent CMV with vasculopathy includes CMV-DNA in tissues removed during surgery for abdominal aortic aneurysm [3]. High CMV antibody titres are linked with increased blood pressure in young men [4] and coronary artery disease requiring surgery [5]. Proposed mechanisms include direct effects of proteins encoded by CMV, such as HCMV US28 - a chemokine receptor homologue that mediates monocyte attachment to endothelial cells [6].

In the absence of anti-viral prophylaxis, symptomatic CMV infections occur in $20-60 \%$ of all transplant recipients and are associated with an increased risk of graft rejection, CMV end organ disease, cardiovascular disease and opportunistic infections [7]. We have demonstrated elevated levels of CMV antibody [8] in renal transplant recipients (RTR) stable more than 2 years after transplantation, suggesting a high persistent viral burden.

Natural killer (NK) cells can control CMV infections in the absence of T-cells. Direct evidence includes a child with a congenital T-cell deficiency who recovered from CMV disease without antiviral therapy and displayed increased populations of NK cells [9]. Hence polymorphisms in genes encoding NK cell receptors may influence an individual's burden of CMV. In addition, NK cells may contribute to vascular pathologies. Patients with coronary artery disease had low numbers of circulating NK cells [10] and patients with coronary heart disease had impaired NK cell cytotoxic activity compared with healthy controls [11]. NK cell function has also been associated with atherosclerosis in mice. Immunohistochemistry revealed NK cells in atherosclerotic lesions of Ly49A transgenic mice and nontransgenic littermates. Atherosclerosis was reduced in mice with a functional NK cell deficiency [12]. If NK cells are indeed important players in cardiovascular disease, then one may expect genetic polymorphisms affecting NK function to have an impact. Here we consider three candidate polymorphisms known to affect expression or function of the encoded protein.

Leukocyte immunoglobulin-like receptor 1 (LIR-1, CD85j/ILT2; encoded by LILRB1) is an NK cell inhibitory receptor that is rapidly induced during CMV infections. LIR-1 can interact with major 
histocompatibility complex class I (MHC-1) proteins [most potently human leucocyte antigen (HLA)G [13] or UL18 (a CMV-encoded MHC-I homologue) to inhibit NK cell cytotoxicity [14]. A nonsynonymous single nucleotide polymorphism (SNP) in LILRB1 (rs1061680) is associated with low nadir CD4 T-cell counts and CMV disease in Caucasian HIV patients [15].

A 14-base pair deletion in the gene encoding HLA-G has been linked with graft rejection in RTR. HLA$\mathrm{G}$ is a non-classical HLA class Ib molecule with limited variability generated by alternative splicing. A 14-bp insertion/deletion polymorphism in exon 8 of the 3' untranslated region of the HLA-G gene can influence levels of soluble HLA-G in plasma [16], as it reduces mRNA stability [17]. The 14bp deletion is more common in RTR with active CMV infections (CMV DNA, pp65 antigenemia or IgM) when compared with recipients stable on therapy [18].

NKG2 molecules belong to the C-type lectin superfamily involved in regulation of NK cell responses. NKG2C interacts with HLA-E to activate NK cellular cytotoxicity. Heterozygous and homozygous carriage of a 16-kb deletion in NKG2C reduces NKG2C expression on NK cells [19]. In a study of healthy blood donors, the deletion affected T-cell and NK cell profiles but did not alter T-cell responses to CMV antigens (IE-1, IE-2 and pp65) [20]. In contrast to this, Gambian children with the NKG2C-1genotype had higher CMV antibody levels when compared with $\mathrm{NKG}_{2} \mathrm{C}^{+/+}$children, but the difference was not apparent in healthy adults from the same community [21].

The importance of NKG2C and LIR-1/HLA-G in the relationship between CMV and its host is underscored by evidence NK cell expression of LIR-1 is an early marker of CMV replication in transplant recipients [e.g.: 22], and has been associated with atherosclerosis [23]. CMV also induces NK cells to express NKG2C [24], and expansions of the NKG2C+ NK cell subset has been associated with unstable carotid atherosclerotic plaques in CMV seropositive patients [25].

Here we studied polymorphisms in LIR-1, HLA-G, NKG2C to illuminate the importance of NK cells as determinants vascular of health and the burden of CMV. Assessments included flow mediated dilatation (FMD) which measures the capacity of a larger conduit artery to dilate in responses to increased shear stress via endothelial dependent and independent mechanisms. Endothelial dependent FMD is regulated by nitric oxide bio-availability which is central to the regulation of renovascular function [26]. Carotid intimal media thickness (cIMT) is a measurement of the thickness of the inner layer (intima) of the carotid artery and is a marker of subclinical atherosclerosis [27]. We 
studied a well-characterized cohort of RTR as we have documented their high burden of CMV in relation to healthy older adults.

\subsection{Materials and Methods:}

\subsection{Study Cohort}

Renal transplant recipients ( $n=82$ ) were recruited from renal clinics at Royal Perth Hospital (Western Australia) and 81 healthy aged-matched controls were recruited from staff and through local advertisements. All RTR were clinically stable $>2$ years post-transplant, had no CMV disease or reactivation within 6 months of sample collection and were not taking anti-viral treatment. RTR infected with hepatitis B or C were excluded from the study. Cardiovascular data (cIMT, plaques and FMD) were assessed by ultrasonography [8]. Ethics approval was provided by Curtin University (HR16/2015) and participants provided written informed consent.

\subsection{Assessments of the burden of CMV}

Plasma and buffy coats were stored at $-80^{\circ} \mathrm{C}$. Peripheral blood mononuclear cells (PBMC) were isolated by Ficoll density centrifugation and cryopreserved in liquid nitrogen. Plasma CMV IgG antibody titres were evaluated using an in-house ELISA assay utilising a lysate of CMV-infected fibroblasts or recombinant CMV gB or IE-1 antigens [28]. Plasma CMV DNA was detected using the Abbot Molecular assay (Abbot Laboratories, Chicago, IL) in the Department of Microbiology (Royal Perth Hospital). Cryopreserved PBMC were used to assess T-cell responses to a lysate of CMVinfected fibroblasts and pp65 [28] and IE-1 antigens (JPT Peptide Technologies; Berlin, Germany) via ELISPOT assays.

\subsection{DNA Extraction and Genotyping}

DNA was extracted from EDTA buffy coat samples using FavorPrep Blood Genomic DNA Extraction Mini Kits (Favorgen, Ping-Tung, Taiwan) and stored at $-80^{\circ} \mathrm{C}$. Samples were diluted to 20ng DNA $/ \mu \mathrm{l}$ for use. A Taqman assay (Applied Biosystems, Foster City, CA) was used to identify LILRB1 rs1061680. A $16 \mathrm{~kb}$ deletion in exon 6 of NKG2C [29] was detected by PCR amplification $\left[96^{\circ} \mathrm{C}\right.$ for 5 minutes followed by 35 cycles of $96^{\circ} \mathrm{C}$ for 30 seconds, $57^{\circ} \mathrm{C}$ for 30 seconds and $72^{\circ} \mathrm{C}$ for 40 seconds]. Amplicons were separated on $1 \%$ agarose gels in $0.5 \times$ TBE buffer. Homozygous wildtype, heterozygous and homozygous deletion are denoted $\mathrm{NKG}_{2} \mathrm{C}^{+/+}, \mathrm{NKG} 2 \mathrm{C}^{+/-}$and $\mathrm{NKG}_{2} \mathrm{C}^{-/-}$respectively. A $14 \mathrm{bp}$ deletion in 
HLA-G [30] was identified by PCR amplification $\left[95^{\circ} \mathrm{C}\right.$ for 5 minutes followed by 35 cycles of $95^{\circ} \mathrm{C}$ for 20 seconds, $60^{\circ} \mathrm{C}$ for 30 seconds and $72^{\circ} \mathrm{C}$ for 30 seconds]. Amplicons were separated on $3 \%$ agarose gels in 0.5×TBE buffer. Homozygous 14bp insertion, heterozygous and homozygous 14bp deletion are denoted $14 \mathrm{bp}^{+/+}, 14 \mathrm{bp}^{+/-}$and $14 \mathrm{bp}^{-/-}$respectively.

\subsection{Statistical Analyses}

Mann-Whitney and Fisher's exact tests utilized GraphPad Prism version 6 for Windows (Graphpad Software, La Jolla CA).

\subsection{Results and Discussion}

\subsection{Controls and RTR were matched demographically and genotype frequencies did not differ}

Eighty-two RTR and 81 healthy controls were screened for polymorphisms in the genes encoding HLA-G, LILRB1 and NKG2C, cardiovascular health and CMV-reactive antibodies. There were no significant differences in gender or ethnicity between the healthy controls and RTR, and the RTR were only marginally older than the controls (Table 1).

RTR had lower FMD values ( $p<0.0001)$, a higher incidence of plaques $(p=0.003)$ and higher antibody responses to CMV lysate, $g B$ and IE- 1 ( $p<0.0001, p<0.0001, p=0.02$ respectively) compared to healthy participants. CIMT values did not differ between RTR and healthy participants. There were no significant differences in the frequencies of any polymorphisms between RTR and healthy controls when assessed by individual genotypes or carriage of the minor allele or deletion (Table 1). Neither CMV sero-negativity (RTR, $n=13$; controls, $n=32$ ) nor ethnicity partitioned with genotype for any of the polymorphisms tested (data not shown). When seronegative individuals were excluded from analyses, the trends were not affected, so data from all individuals are presented.

CMV DNA was assessed in plasma samples from 77 RTR and 10 controls. Just 16 samples (all from RTR) contained CMV DNA. Of these only 7 had over 20 copies/ $\mathrm{mL}$ - the remainder were reported as having low but detectable DNA. Hence analyses of the effects of genotype on the detection of CMV DNA lacked statistical power and are not reported.

4.2 HLA-G polymorphism may affect vascular health 
The $14 \mathrm{bp}^{+/+}$genotype is less prevalent than $14 \mathrm{bp}^{-/-}$in these cohorts, as in our study of Caucasian and African American HIV patients [15]. RTR with the $14 \mathrm{bp}^{+/-}$HLA-G genotype presented with higher FMD values (Fig $1 \mathrm{~A}, \mathrm{p}=0.04$ ), suggest more flexible arteries compared to RTR with the $14 \mathrm{bp}^{-/-}$genotype. FMD vales were not elevated in individuals with $14 \mathrm{bp}^{+/+}$, but there were only 9 RTR with this genotype. In accordance with the FMD data, RTR with the $14 \mathrm{bp}^{+/-}$genotype had marginally lower cIMT values (Fig 1B, p=0.096) suggesting a lower risk of subclinical atherosclerosis [27]. This supports a link between NK cell activity and atherosclerosis.

We found no associations between the HLA-G indel and measures of CMV (T-cells or antibody). This is illustrated using CMV lysate antibody in Supplementary Fig 1. We also found no association with CMV seropositivity per se (14bp $\mathrm{b}^{+/+}$and $14 \mathrm{bp}^{+/-}$vs $14 \mathrm{bp}^{-/-}, \mathrm{p}=1.0$ ), but cannot rule out an effect on CMV replication as Jin et al [19] linked carriage of the 14bp deletion in RTR with CMV pp65 antigenemia, DNA or IgM within 6 months of transplantation.

\subsection{LILRB1 SNP creates paradox when comparing FMD and cIMT}

RTR carrying the T allele of LILRB1 rs1061680 had elevated FMD (Fig 1C, TT vs TC, $\mathrm{p}=0.03$ ). This is illustrated in Figure $1 \mathrm{C}$ showing that TT homozygote carriers had the highest FMD values. Additionally, TT homozygotes carriers had less cardiac events (TT vs TC, $p=0.047$, data not shown). However this group also had the highest cIMT values (Fig 1D). This paradox was not evident in healthy controls where carriage of the T allele was associated with elevated cIMT (Fig 1F, TT vs CC, $p=0.009$ and TC vs CC, $p=0.004$ ) and marginally lower FMD (Fig 1E, p=0.2, $p=0.097$, resp.).

We considered the possibility that the discrepancy between RTR and controls may reflect the greater burden of CMV in the RTR. However there were no associations between LILRB1 rs1061680 alleles and CMV lysate antibodies (Supplementary Fig 1) or other measures of CMV burden described in Table 1 (data not shown). We previously linked the C allele with CMV disease in Caucasian HIV patients, but aligned the finding with very low nadir CD4 T-cell counts [15], so we have no evidence of a direct effect on the control of CMV. Accordingly it is possible that the vascular changes seen here reflect other risk factors. 
Heterozygosity for the 16-kb deletion reduces surface expression of NKG2C [29] including that induced by CMV [24]. The NKG2C-/- genotype was rare (RTR $n=5$, controls $n=6)$, precluding statistical analyses of these individuals. However compared with $\mathrm{NKG}_{2} \mathrm{C}^{+/-}$genotype, individuals with $\mathrm{NKG}_{2} \mathrm{C}^{+/+}$ genotype had higher cIMT (Fig 1G, p=0.007), lower T-cell responses to CMV IE-1 (Fig 1H, p=0.02), lower levels of CMV gB antibodies (Fig 1I, p=0.04) and marginally lower levels of CMV lysate antibody (Supp Fig 1, $\mathrm{p}=0.07$ ). This aligns with better cardiovascular health in $\mathrm{NKG} \mathrm{C}^{+/-}$individuals with high adaptive responses to CMV. We can interpret this data in two ways. The first is that cardiovascular health is improved in the $\mathrm{NKG}_{2} \mathrm{C}^{+/}$group due to the decreased expression of $\mathrm{NKG} 2 \mathrm{C}$. Expression of NKG2C has been linked with unstable carotid atherosclerotic plaques [25]. Secondly low cIMT values may reflect better control of intermittent CMV replication by $B$ and T-cells. When NK function is impaired by the NKG2C deletion, it is plausible that this drives $B$ and T-cell responses to compensate for the decreased NK cytotoxicity. Although the NKG2C deletion did not affect CMV-specific T-cell responses in healthy adults here (data not shown) or in a previous study [20], it is plausible that it might do so in individuals with a high burden of CMV - such as RTR.

\subsection{Conclusions}

In conclusion, we provide preliminary evidence that LIR-1/HLA-G pathways may impact upon cardiovascular health, but the polymorphisms tested did not impact upon the burden of CMV as assessed by adaptive immune responses to CMV antigens. In contrast, the $16 \mathrm{~kb}$ deletion in NKG2C known to affect expression of this ligand increased adaptive responses to CMV and associated with cardiovascular health as assessed by cIMT in RTR. Larger prospective studies are needed to explore the effect of the NKG2C deletion on adaptive immune responses to CMV and other viruses with a potential to affect vascular health. 


\subsection{Acknowledgements}

The authors thank all individuals who participated in this study and acknowledge the Curtin Health Innovation Research Institute for provision of laboratory space and technology platforms.

Conflicts of interest: none to declare

Figure 1. Effects of LILRB1 SNP, HLA-G 14bp and NKG2C polymorphisms on FMD, cIMT and responses to $\mathrm{CMV}$.

A. Compares HLA-G genotype with FMD in RTR. B. Compares HLA-G genotype with average cIMT in RTR. C. Compares LILRB1 SNP genotype with FMD in RTR. D. Compares LILRB1 SNP genotype with average cIMT in RTR. E. Compares LILRB1 SNP genotype with FMD in healthy controls. F. Compares LILRB1 SNP genotype with average cIMT in healthy controls G. Compares NKG2C genotype with average cIMT in RTR. H. Compares NKG2C genotype with IE-1 T-cell responses in RTR (reported as spot forming units per 200,000 cells). I. Compares NKG2C genotype with gB antibody levels in RTR.

Supplementary Figure 1. Comparison of CMV lysate antibody levels with HLA-G, LILRB1 and NKG2C genotype in RTR and healthy controls.

This figure shows CMV lysate IgG antibody levels (AU) compared with the genotype groups in each genetic polymorphism that was analysed. 


\section{References:}

1. Manicklal, S., Emery VC, Lazzarotto T, Boppana SB, Gupta RK. The "silent" global burden of congenital cytomegalovirus. Clin Microbiol Rev. 26 (2013):86-102.

2. Pawelec G, Derhovanessian E. Role of CMV in immune senescence. Virus Res. 157 (2011):175179.

3. Gredmark-Russ S Dzabic $M$, Rahbar A, Wanhainen A, Björck $M$, Larsson E, Michel JB, Söderberg-Nauclér C. Active CMV infection in aortic smooth muscle. J Mol Med. 87 (2009):347-356.

4. Haarala A, Kähönen $M$, Lehtimäki T, Aittoniemi J, Jylhävä J, Hutri-Kähönen N, Taittonen L, Laitinen T, Juonala M, Viikari J, Raitakari OT, Hurme M. Relation of high CMV antibody to blood pressure Clin Exp Immun. 167 (2012):309-316.

5. Safaie N, Ghotaslou R, Montazer Ghaem H. Seroprevalence of cytomegalovirus in patients with and without coronary artery diseases at Madani Heart Center, Iran. Acta Med Iran. 48 (2010):403-406.

6. Wu SE, Miller WE. The HCMV US28 vGPCR induces potent G $\alpha$ q/PLC- $\beta$ signaling in monocytes leading to increased adhesion to endothelial cells. Virology. 497 (2016):233-243.

7. Cukuranovic J, Ugrenovic S, Jovanovic I, Visnjic M, Stefanovic V. Viral infection in renal transplant recipients. Scientific World Journal. 2012, p. 820621. doi: 10.1100/2012/820621.

8. Price P, Lee S, Affandi J, Parsons R, Naylor LH, Watts GF, Irish A. Cytomegalovirus antibody and vascular pathology in renal transplant recipients. J Med Virol. 89 (2017):177-181.

9. Kuijpers TW, Baars PA, Dantin C, van den Burg M, van Lier RA, Roosnek E. Human NK cells can control CMV infection in the absence of T cells. Blood. 112 (2008):914-915.

10. Backteman K, Ernerudh J, Jonasson L. Natural killer (NK) cell deficit in coronary artery disease: no aberrations in phenotype but sustained reduction of NK cells is associated with low-grade inflammation. Clin Exp Immunol. 175 (2014):104-112.

11. Hak L, Mys'liwska J, Więckiewicz J, Szyndler K, Trzonkowski P, Siebert J, Mys'liwski A. NK cell compartment in patients with coronary heart disease. Immunity \& Ageing. 4 (2007):doi:10.1186/1742-4933-4-3.

12. Whitman SC, Rateri DL, Szilvassy SJ, Yokoyama W, Daugherty A. Depletion of natural killer cell function decreases atherosclerosis in low-density lipoprotein receptor null mice. Arterioscler Thromb Vasc Biol. 24 (2004):1049-1054.

13. Shiroishi M, Kuroki K, Rasubala L, Tsumoto K, Kumagai I, Kurimoto E, Kato K, Kohda D, Maenaka K. Human inhibitory receptors Ig-like transcript 2 (ILT2) and ILT4 compete with CD8 
for MHC class I binding and bind preferentially to HLA-G. Proc Natl Acad Sci U S A. 100 (2003): 8856-8861.

14. Yang Z, Bjorkman PJ. Structure of UL18, a peptide-binding viral MHC mimic, bound to a host inhibitory receptor. Proc Natl Acad Sci U S A. 105 (2008):10095-10100.

15. Affandi, J.S., Aghafar ZK, Rodriguez B, Lederman MM, Burrows S, Senitzer D, Price P. Can immune-related genotypes illuminate the immunopathogenesis of cytomegalovirus disease in human immunodeficiency virus-infected patients? Human Immunol. 73 (2012):168-174.

16. Chen XY, Yan W,. Lin A, Xu HH, Zhang JG, Wang XX. The 14 bp deletion polymorphisms in HLA$G$ gene play an important role in the expression of soluble HLA-G in plasma. Tissue Antigens. 72 (2008):335-341.

17. Rousseau P, Discorde ML, Mouillot G, Carosella ED, Moreau P. The 14 bp Deletion-Insertion polymorphism in the 3'UT region of the HLA-G gene influences HLA-G mRNA stability. Human Immunol. 64 (2003): 1005-1010.

18. Jin ZK, Xu CX, Tian PX, Xue WJ, Ding XM, Zheng J, Ding CG, Ge GQ, Mao TC, Lin Y. Impact of HLA-G 14-bp polymorphism on acute rejection and cytomegalovirus infection in kidney transplant recipients from northwestern China. Transpl Immunol. 27 (2012):69-74.

19. Hikami K, Tsuchiya N, Yabe T, Tokunaga K. Variations of human killer cell lectin-like receptors: common occurrence of NKG2-C deletion in the general population. Genes Immunol. 4 (2003):160-167.

20. Liu LL, Landskron J, Ask EH, Enqvist M, Sohlberg E, Tranherne JA, Hammer Q, Goodridge JP, Larsson S, Jayaraman J, Oei VYS, Schaffer M, Tasken Q, Ljunggren H, Romagnani C, Trowsdale J, Malmberg K, Beziat V. Critical role of CD2 co-stimulation in adaptive natural killer cell responses revealed in NKG2C-deficient humans. Cell Reports. 15 (2016):1088-1099.

21. Goodier MR, White MJ, Darboe A, Nielsen CM, Goncalves A, Bottomley C, Moore SE, Riley EM. Rapid NK cell differentiation in a population with near-universal human cytomegalovirus infection is attenuated by NKG2C deletions. Blood. 124 (2014):2213-2222.

22. Wagner CS Riise GC, Bergström T, Kärre K, Carbone E, Berg L. Increased expression of LIR-1 and activating role of UL18 in the response to cytomegalovirus infection. J Immunol. 178 (2007):3536-3543.

23. Romo N, Magri G, Muntasell A, Heredia G, Baía D, Angulo A, Guma M, López-Botet M. Association of atherosclerosis with expression of the LILRB1 receptor by human NK and T-cells supports the infectious burden hypothesis. Arterioscler Thromb Vasc Biol. 31 (2011):2314-21.

24. Makwana NB, Foley B, Lee S, Fernandez S, Irish AB, Price P. Asymptomatic CMV infections in long-term renal transplant recipients are associated with the loss of FcRgamma from LIR-1+ NK cells. Eur J Immunol. 46 (2016):2597-2608. 
25. Martínez-Rodríguez JE, Munné-Collado J, Rasal R, Cuadrado E, Roig L, Ois A et al. Expansion of the NKG2C+ natural killer-cell subset is associated with high-risk carotid atherosclerotic plaques in seropositive patients for human cytomegalovirus. Arterioscler Thromb Vasc Biol. 33 (2013):2653-2659.

26. Delles C, Klingbeil AU, Schneider MP, Handrock R, Schaufele T, Schmieder RE. The role of nitric oxide in the regulation of glomerular haemodynamics in humans. Nephrol Dial Transplant. 19 (2004):1392-1397.

27. de Groot E, Hovingh K, Wiegman A, Duriez P, Smit AJ, Fruchart J, Kastelein JPJ. Measurement of Arterial Wall Thickness as a Surrogate Marker for Atherosclerosis. Circulation. 109 (2004): doi: 10.1161/01.CIR.0000131516.65699.ba.

28. Affandi JS, Montgomery J, Brunt SJ, Nolan D, Price P. The immunological footprint of CMV in HIV-1 patients stable on long-term ART. Immun Ageing. 12 (2015):doi: 10.1186/s12979-0150041-0.

29. Miyashita R, Tsuchiya N, Hikami K, Kuroki K, Fukazawa T, Bijl M, Kallenberg CGM, Hashimoto $\mathrm{H}$, Yabe T, Tokunaga K. Molecular genetic analyses of human NKG2C (KLRC2) gene deletion. Int Immunol. 16 (2004):163-168.

30. Lin A, Yan WH, Xu HH, Tang LJ, Chen XF, Zhu M, Zhou MY. 14 bp deletion polymorphism in the HLA-G gene is a risk factor for idiopathic dilated cardiomyopathy in a Chinese Han population. Tissue Antigens. 70 (2007):427-431. 


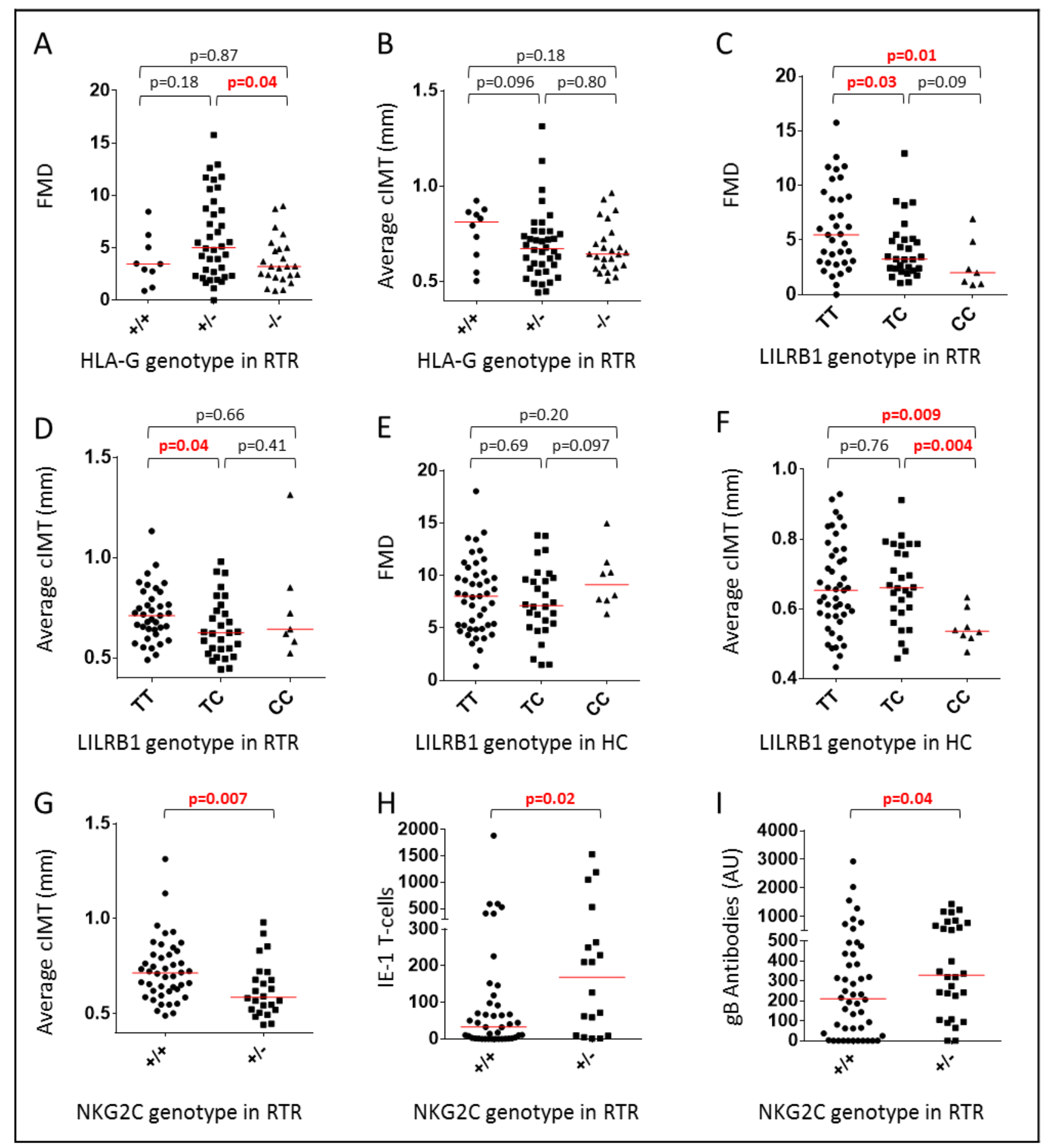

Figure 1 
Table 1. Comparison of demographics, cardiovascular measures, CMV measures and genotype frequencies between RTR and health controls.

\begin{tabular}{|c|c|c|c|c|}
\hline $\mathrm{n}$ & $\begin{array}{c}\text { RTR } \\
82 \\
\end{array}$ & $\begin{array}{c}\text { Control } \\
81 \\
\end{array}$ & \multicolumn{2}{|c|}{ P-value ${ }^{a}$} \\
\hline \multicolumn{5}{|l|}{ Demographic measures } \\
\hline Age (years) & $57(31-76)$ & $54(21-86)$ & \multicolumn{2}{|c|}{0.07} \\
\hline Male / Female & $46 / 36$ & $37 / 43$ & \multicolumn{2}{|c|}{0.27} \\
\hline Caucasian/Asian & $69 / 8$ & $71 / 9$ & \multicolumn{2}{|c|}{1.00} \\
\hline \multicolumn{5}{|c|}{ Cardiovascular measures } \\
\hline FMD & $3.9(0-15.8)$ & $7.9(1.4-18)$ & \multicolumn{2}{|c|}{$<0.0001$} \\
\hline Average cIMT (mm) & $0.66(0.44-1.31)$ & $0.64(0.43-0.93)$ & \multicolumn{2}{|c|}{0.15} \\
\hline Plaques & Yes $=10, \mathrm{No}=63$ & Yes $=1, \mathrm{No}=80$ & \multirow{2}{*}{\multicolumn{2}{|c|}{0.003}} \\
\hline Cardiac event & Yes $=30, \mathrm{No}=46$ & None reported & & \\
\hline \multicolumn{5}{|c|}{ Measures of the burden of CMV } \\
\hline CMV Seropositive & $69(84 \%)$ & $49(60 \%)$ & \multirow{8}{*}{\multicolumn{2}{|c|}{$\begin{array}{c}<0.0001 \\
<0.0001 \\
0.02 \\
0.55 \\
0.21 \\
0.07\end{array}$}} \\
\hline CMV Seronegative & $13(16 \%)$ & $32(40 \%)$ & & \\
\hline CMV lysate antibodies & $605(0-7611)$ & $56(0-1496)$ & & \\
\hline gB antibodies & $246(0-2932)$ & $56(0-401)$ & & \\
\hline IE-1 antibodies & $96(5-4775)$ & $63(9-1565)$ & & \\
\hline CMV lysate T-cells ${ }^{b}$ & $45(0-1207)$ & $23(0-1938)$ & & \\
\hline pp65 T-cells ${ }^{b}$ & $147(0-1490)$ & $26(0-1880)$ & & \\
\hline IE-1 T-cells ${ }^{b}$ & $25(0-593.5)$ & $4.5(0-1304)$ & & \\
\hline \multicolumn{5}{|c|}{$\begin{array}{l}\text { Genotypes linked to NK function } \\
\text { HLA-G }\end{array}$} \\
\hline $14 \mathrm{bp}^{+/+}$ & 12 & 13 & & \multirow{3}{*}{$1.0^{d}$} \\
\hline $14 \mathrm{bp}^{+/-}$ & 44 & 45 & $1.0^{c}$ & \\
\hline $14 b p^{-/-}$ & 26 & 22 & 1.0 & \\
\hline \multicolumn{5}{|l|}{ LILRB1 } \\
\hline TT & 42 & 45 & & \multirow{3}{*}{1.0} \\
\hline $\mathrm{TC}$ & 33 & 28 & 0.51 & \\
\hline $\mathrm{CC}$ & 7 & 8 & 0.77 & \\
\hline \multicolumn{5}{|l|}{ NKG2C } \\
\hline $\mathrm{NKG}_{2 \mathrm{C}^{+/+}}$ & 48 & 51 & & \multirow{3}{*}{1.0} \\
\hline $\mathrm{NKG} 2 \mathrm{C}^{+/-}$ & 28 & 24 & 0.61 & \\
\hline NKG2C ${ }^{-/-}$ & 5 & 6 & 0.74 & \\
\hline
\end{tabular}

a Mann Whitney or Fishers Exact tests

${ }^{b}$ T-cell responses ( $\gamma$-interferon production) are reported as spot forming units per 200,000 cells

${ }^{c}$ Compared the homozygote wildtype (WT) with the heterozygotes

${ }^{\mathrm{d}}$ Compared the homozygote wildtype with the homozygote deletions (Del) 


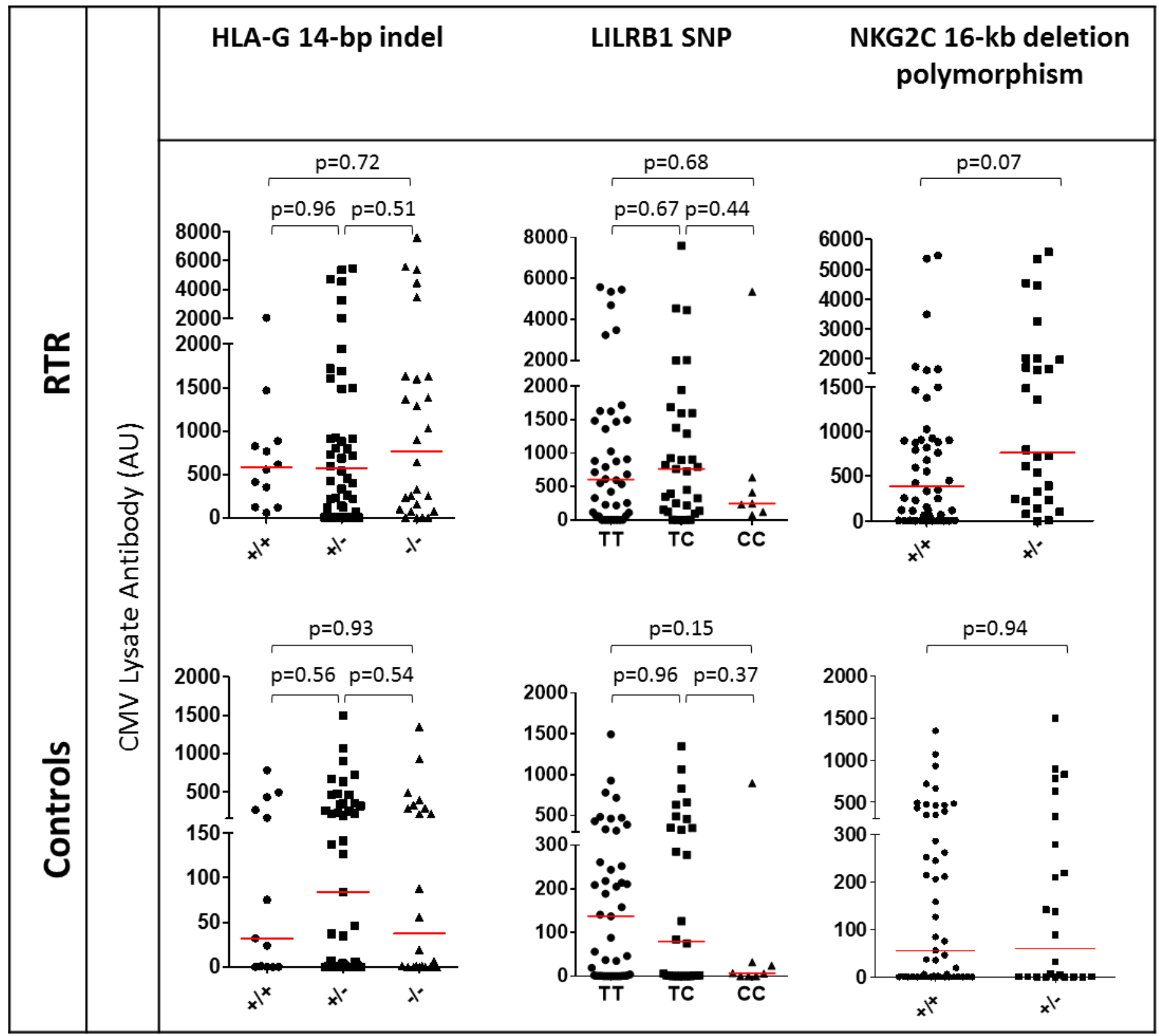

Supplementary Figure 1 


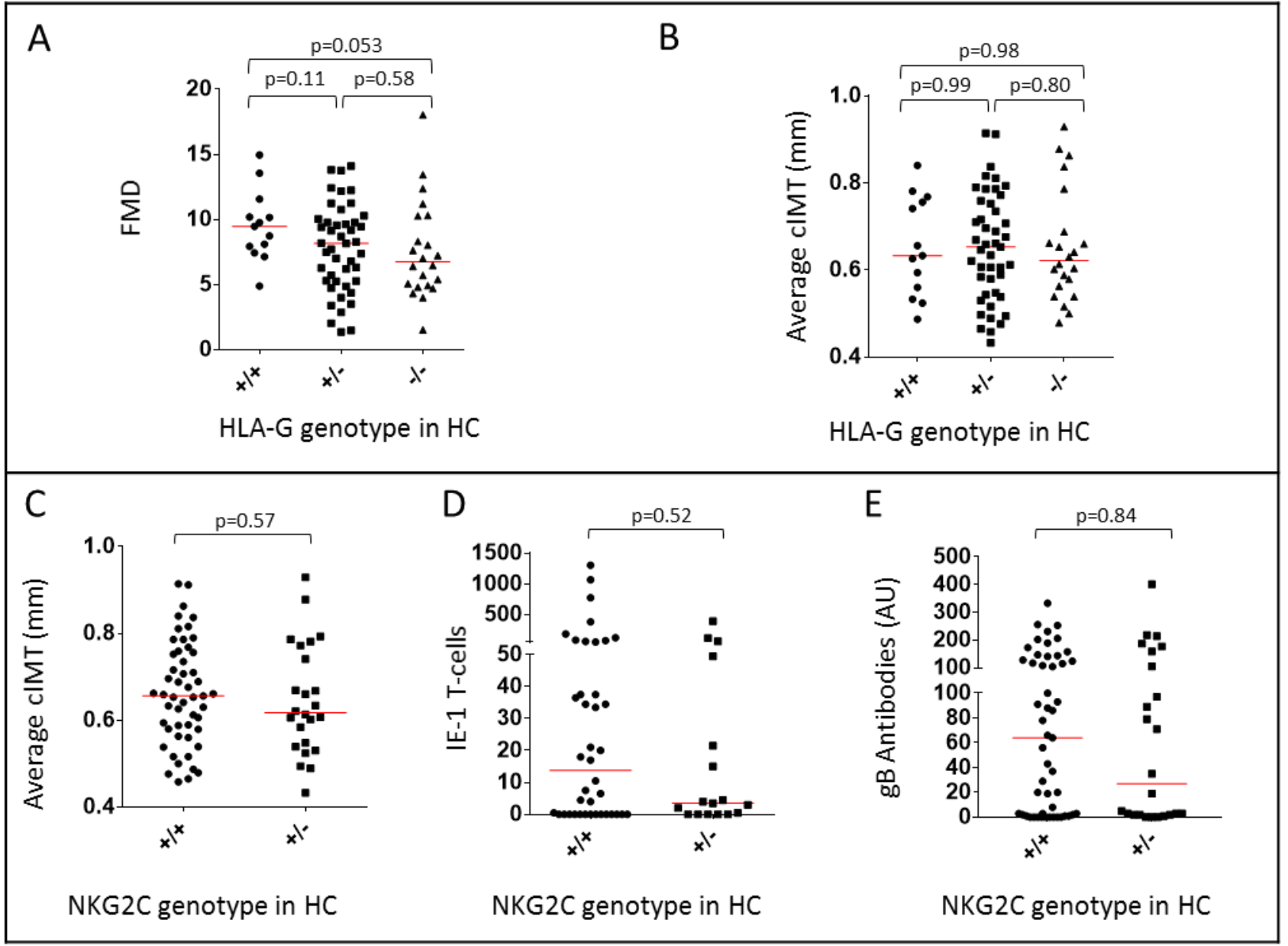

Supplementary Figure 2 